\title{
Cuticular Fractures Promote Postharvest Fruit Rot in Sweet Cherries
}

Jorunn Børve and Lars Sekse, The Norwegian Crop Research Institute, Ullensvang Research Centre, N-5781 Lofthus, Norway; and Arne Stensvand, The Norwegian Crop Research Institute, Plant Protection Centre, Fellesbygget, N-1432 Ås, Norway

\begin{abstract}
Børve, J., Sekse, L., and Stensvand, A. 2000. Cuticular fractures promote postharvest fruit rot in sweet cherries. Plant Dis. 84:1180-1184.

Preharvest cuticular fractures in sweet cherry fruit have been suggested to facilitate pathogen invasion, and a method to classify the mount of cuticular fracturing into five categories (from 1 $=$ no visible fractures to $5=$ severe fracturing) has previously been proposed. Sweet cherry fruit of the four cultivars Early Burlat, Lapins, Van, and Vista were sorted into these five categories of cuticular fracturing and inoculated with conidial suspensions of either Botrytis cinerea or Monilinia laxa. After incubating the fruit at $20^{\circ} \mathrm{C}$ and $100 \%$ relative humidity for 4 to 7 days, they were assessed for visible fungal growth. Due to quiescent infections of $M$. laxa, fruit treated with $B$. cinerea developed more brown rot than gray mold. However, a significant linear relation $(P<0.05)$ between the amount of cuticular fracturing and fungal infections was obtained in five of seven trials with $B$. cinerea and in two of four trials with $M$. laxa, indicating that fungal infections in sweet cherry fruit may be facilitated by cuticular fractures. Independent of cultivar and year, a significant linear relation was found between the category of cuticular fracturing and percentage of infected fruit after inoculation with both $B$. cinerea and $M$. laxa, and in control fruit $(P=0.0001,0.0183$, and 0.0182 , respectively). This is the first report quantifying an increase in fungal infection with increasing amount of cuticular fracturing. The mean difference in fruit rot $(\%) \pm$ standard deviation among fruit in fracturing categories 1 and 5, expressed as the linear contrast of amount of fruit rot in category 5 minus amount of fruit rot in category 1 , was $37.2 \pm 7.4(P=0.0001), 35.4 \pm 11.0(P=0.0022), 17.0 \pm 6.7(P=0.0135)$, and $29.8 \pm 4.7(P=0.0001)$, after treatments with $B$. cinerea, $M$. laxa, water control, and for all data pooled, respectively.
\end{abstract}

Additional keywords: brown rot, gray mold, Mucor piriformis, Prunus avium
Brown rot and gray mold caused by the ascomycetes Monilinia laxa (Aderhold \& Ruhland) Honey (anamorph: Monilia laxa (Ehrenb.) Sacc. \& Voglino) and Botryotinia fuckeliana (de Bary) Whetzel (anamorph: Botrytis cinerea Pers. ex Fr.), respectively, are the most important diseases of sweet cherry (Prunus avium L.) fruit in Norway. In Norway, the perfect stages of the fungi have not been found. The anamorphs apparently dominate as inoculum. Disease incidence of $M$. laxa and $B$. cinerea is increased by wounds and weakened tissue, which provide more abundant moisture and nutrients for spore germination and mycelial growth of both $M$. laxa (5) and B. cinerea (8) in fleshy fruit. Generally, the cuticle of fruit is known to have a protective role and, in sweet cherry fruit, the cuticle has been reported to take part in resistance against Monilinia fructicola (4).

Corresponding author: A. Stensvand

E-mail: arne.stensvand@planteforsk.no

Accepted for publication 5 July 2000.

Publication no. D-2000-0831-02R

(C) 2000 The American Phytopathological Society
At harvest, sweet cherry fruit with cracks and other culls are discarded to avoid postharvest fruit rot, whereas fruit with only minor and nearly invisible wounds, such as cuticular fractures, are usually regarded as fully marketable. However, preharvest cuticular fractures have been suggested as possible entry sites for fungal pathogens into sweet cherry fruit $(11,19)$, even though cuticular fractures of sweet cherry fruit have been reported to affect the cuticle, and only occasionally the outer epidermal cells (11) contradictory to cracks that penetrate more or less deep into the fruit flesh.

The objective of the present work was to study possible effects of cuticular fracturing on invasion of sweet cherry fruit by fungal pathogens. A preliminary report of this study has been published previously (3).

\section{MATERIALS AND METHODS}

The investigations were carried out during 1996 to 1998 at Ullensvang Research Centre, located in western Norway. Fruit of the sweet cherry cultivars Early Burlat, Vista, Van, and Lapins were used in these experiments. In Norway, the first two cultivars ripen in early to mid-July, whereas the latter two are harvested in early to mid-August. Variables consisted of rootstocks, whether the trees were covered with polyethylene sheets to prevent fruit cracking during rain the last 3 to 4 weeks prior to harvest, inoculum, dates of inoculation, and number of days from inoculation to assessment (Table 1). The experimental trees were sprayed 3 to 4 times with fungicides from flowering to harvest, except Van in 1996, which was unsprayed. Ripe fruit were picked with stems and sorted (after using a stereo magnifier) into five cuticular fracture categories (18; Fig. 1 ), where $1=$ no cuticular fractures; $2=1$ to 5 minute fractures; $3=$ a few fractures limited to a small part of the fruit surface; and 4 and $5=$ many distinct fractures covering smaller and larger parts of the surface, respectively. The rating was limited to fractures in the area surrounding the stylar scar of the fruit (Fig. 1). Fruit were sorted into the five fracture categories, establishing subsamples (replicates) of
Table 1. Three years of experiments with sweet cherry fruit by cultivar, rootstock, rain cover, inoculum, date of inoculation, and incubation time

\begin{tabular}{|c|c|c|c|c|c|}
\hline Year, cultivar & Rootstock & Rain $\operatorname{cover}^{x}$ & Inoculum $^{y}$ & $\begin{array}{c}\text { Date of } \\
\text { inoculation }\end{array}$ & $\begin{array}{l}\text { Incubation } \\
\text { time (days) }\end{array}$ \\
\hline \multicolumn{6}{|l|}{1996} \\
\hline Vista & $\mathrm{F} 12 / 1$ & Covered & B.c. & 12 August & 4 \\
\hline Van & Colt & Uncovered & B.c. & 19 August & 7 \\
\hline \multicolumn{6}{|l|}{1997} \\
\hline Van & Damil & Covered & B.c. & 6 August & 5 \\
\hline Lapins & Seedling & Covered & B.c. or M.1. & 15 August & 6 \\
\hline \multicolumn{6}{|l|}{1998} \\
\hline Early Burlat & Colt & Uncovered & B.c. or M.1. & 16 July & 4 \\
\hline Vista & Seedling & Covered & B.c. or M.1. & 31 July & 4 \\
\hline Lapins & Inmil & Covered & B.c. or M.1. & 18 August & 6 \\
\hline
\end{tabular}

${ }^{x}$ Whether the trees were covered with polyethylene sheets against cracking or uncovered the last 3 to 4 weeks prior to harvest.

y B.c. = Botrytis cinerea and M.1. = Monilinia laxa .

${ }^{\mathrm{z}}$ Number of days the fruit were incubated in saturated air at $20^{\circ} \mathrm{C}$ from time of inoculation. 
fruit from each category, all with three replicates. The subsamples normally contained 20 fruit each, except in 1996, when only 8 fruit for each replicate in fracture category 5 were included; in 1997 when there were 16 and 18 fruit for each replicate in categories 5 and 4, respectively; and in 1998, when there were 18 fruit for each replicate in category 1.

Fruit were dipped in conidial suspensions of either B. cinerea or M. laxa for 1 min. The suspensions contained $10^{5}$ conidia/ml (Vista in 1998 was treated with $M$. laxa at $3 \times 10^{5}$ conidia/ml). Suspensions of $B$. cinerea were made from an isolate provided by the Norwegian Agricultural University at Ås, except for Early Burlat in 1998 , which was dipped in a conidial suspension made of fruit picked from trees in the experimental orchard of Ullensvang Research Centre and naturally infected with gray mold. The $B$. cinerea isolate originated from strawberry and was grown on potato dextrose agar 2 to 4 weeks prior to inoculation. Suspensions of M. laxa were made from heavily infected fruit collected on trees in the experimental orchard of Ullensvang Research Centre. Infected fruit were shaken in distilled water, and the suspensions were adjusted after counts in a hemacytometer under a light microscope. Viability of conidia was recorded after storing suspension droplets on microscope glass slides for $24 \mathrm{~h}$ at room temperature in moist chambers (sealed plastic boxes). The percentage of germinated conidia varied between 50 and $100 \%$. Occasionally, the germination was lower, most likely because of evaporation of water from the suspension droplets prior to assessment. Fruit treated with distilled water served as controls, and the control fruit were either dipped in water (1996 and 1997) for 1 min or misted with a hand sprayer (1998). The fruit were not surface sterilized prior to inoculation.

Immediately after inoculation, fruit were incubated separately on grids made of chicken wire in plastic boxes containing moist tissue papers covering the inside bottoms to maintain saturated air. The boxes were wrapped in polyethylene bags and placed in constant fluorescent light at $20^{\circ} \mathrm{C}$. After incubation for either 4 (Early Burlat and Vista) or 5 to 7 days (Van and Lapins), each fruit was assessed for visible disease symptoms and sporulation of $B$. cinerea, $M$. laxa, or other fungi causing decay, including Mucor piriformis E. Fisch. Fungal characteristics were examined macroscopically but confirmed by means of light microscope when necessary.

Weather data was provided from a meteorological station located at Ullensvang Research Centre. Disease incidence was statistically analyzed using the GLM procedure of SAS software (SAS Institute, Cary, NC), and all experiments were analyzed separately. Orthogonal polynomials were made to find linear or quadratic relations between disease incidence and fracturing category. Further, a linear contrast in category of cuticular fracturing (category 5 minus category 1) was made for each treatment (inoculation with either $B$. cinerea, Monilinia laxa, or uninoculated) on the whole dataset. All groups of observations were weighted compared to number

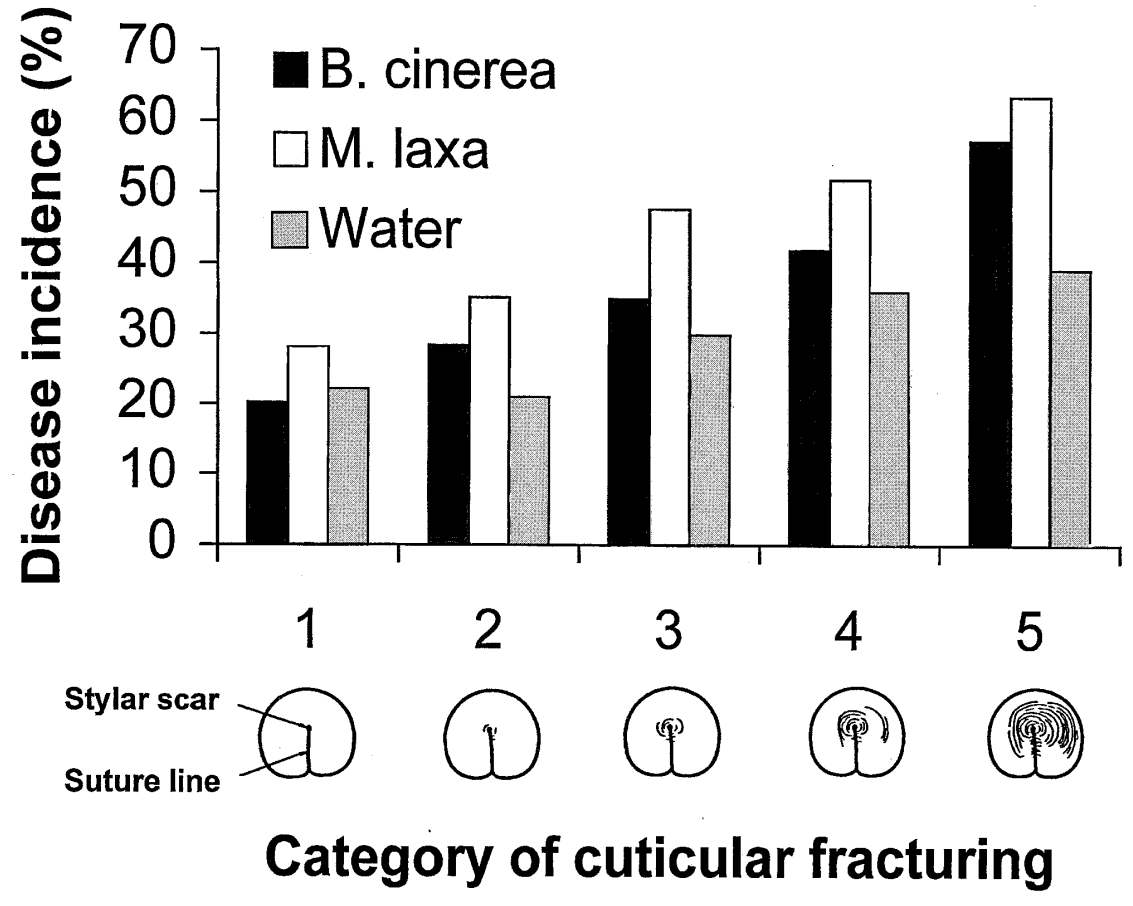

Fig. 1. The effect of cuticular fracturing (on a scale of 1 to 5) in sweet cherry fruit on disease incidence (\%) after treatments with Botrytis cinerea (seven trials), Monilinia laxa (four trials), or water control (seven trials) followed by incubation for 4 to 7 days at $20^{\circ} \mathrm{C}$. Each trial contained three replicates. of fruit included in the observation by the procedure WEIGHT.

\section{RESULTS}

The period June 1 to August 31 (fruit development period) in 1996 to 1998 differed in weather conditions (Table 2). In 1996, June and July were cooler than normal, but August was warm. Precipitation was high in June 1996, but lower than normal in July and August. June to August 1997 was warm and had less than normal precipitation. In 1998, the temperature was below normal and precipitation was higher and more frequent than in the previous two years. In August 1998, it was unusually wet.

The main disease present after storage was brown rot, both in fruit inoculated with $B$. cinerea and $M$. laxa and in control fruit, with the exception of fruit of Lapins in 1998, where Mucor-rot dominated (Table 3). Fruit treated with conidial suspensions of $B$. cinerea developed more brown rot than gray mold after all inoculations (Table 3). A comparison between the percentage of fruit developing gray mold in noninoculated control fruit and fruit inoculated with $B$. cinerea showed a significant difference in the trials with Van (1996 and 1997). The effect of inoculation with $M$. laxa was significant, with a higher percentage of fruit with brown rot after inoculation than in noninoculated fruit in three of four trials (Table 3).

In five of seven trials where fruit were inoculated with $B$. cinerea, a significant linear relation between category of cuticular fracturing and percentage of fruit rot was obtained (Table 4). After inoculation with $M$. laxa, there was a significant linear relation in two of four trials, whereas fruit treated with distilled water showed a significant linear relation between pathogen invasion and amount of cuticular fracturing in one of seven trials. Independent of cultivar and year, a significant linear relation was found between the category of cuticular fracturing and percentage of infected fruit after inoculation, both for $B$. cinerea and $M$. laxa $(P=0.0001$ and 0.0183 , respectively). Similar results for control fruit were significant as well $(P=0.0182)$. None of the polynomials for quadratic relation between category of cuticular fracturing and fruit rot were significant. The mean values for treatments with $B$. cinerea, $M$. laxa, or water, independent of cultivar and year, are presented in Figure 1. The mean difference in fruit rot $(\%) \pm$ standard deviation (SD) between fruit in fracturing categories 1 (no visible fracturing) and 5 (severe fracturing), expressed as the linear contrast of percentage of fruit rot in category 5 minus amount of fruit rot in category 1 , was $37.2 \pm 7.4(P=0.0001)$, $35.4 \pm 11.0(P=0.0022)$, and $17.0 \pm 6.7(P$ $=0.0135)$ after treatments with $B$. cinerea, $M$. laxa, and water control, respectively. Independent of treatment (data for B. cine- 
Table 2. Monthly mean temperature $\left({ }^{\circ} \mathrm{C}\right)$, sum precipitation $(\mathrm{mm})$, and number of days with precipitation above 0.2 mm, from 1 June to 31 August 1996 to 1998, obtained from a weather station at Ullensvang Research Centre

\begin{tabular}{|c|c|c|c|c|c|c|c|c|c|}
\hline \multirow[b]{2}{*}{ Year } & \multicolumn{3}{|c|}{ June (1-30) } & \multicolumn{3}{|c|}{ July (1-31) } & \multicolumn{3}{|c|}{ August (1-31) } \\
\hline & Temperature & Precipitation & Days & Temperature & Precipitation & Days & Temperature & Precipitation & Days \\
\hline 1996 & 13.2 & 71 & 16 & 14.1 & 22 & 13 & 16.9 & 41 & 13 \\
\hline 1997 & 15.8 & 16 & 11 & 17.8 & 31 & 18 & 18.6 & 57 & 12 \\
\hline 1998 & 12.6 & 84 & 19 & 13.9 & 68 & 25 & 13.2 & 152 & 20 \\
\hline Normal $^{\mathrm{z}}$ & 14.1 & 59 & $\ldots$ & 15.2 & 74 & $\ldots$ & 14.4 & 86 & $\ldots$ \\
\hline
\end{tabular}

${ }^{\mathrm{z}}$ Normal values are means for 1961 to 1990 .

Table 3. Incidence of Botrytis cinerea, Monilinia laxa, and Mucor piriformis in sweet cherry fruit after treatments with B. cinerea, Monilinia laxa, or water control followed by incubation for 4 to 7 days at $20^{\circ} \mathrm{C}^{\mathrm{y}}$

\begin{tabular}{|c|c|c|c|c|}
\hline \multirow[b]{2}{*}{ Cultivar, year ${ }^{\mathrm{z}}$} & \multirow[b]{2}{*}{ Inoculum } & \multicolumn{3}{|c|}{ Incidence $(\%) \pm$ standard deviation } \\
\hline & & B. cinerea & Monilinia laxa & Mucor piriformis \\
\hline \multirow[t]{2}{*}{ Van, 1996} & B. cinerea & $14.1 \pm 13.6 \mathrm{a}$ & $28.6 \pm 11.8 \mathrm{a}$ & $2.7 \pm 3.3 \mathrm{a}$ \\
\hline & Water & $3.2 \pm 4.1 \mathrm{~b}$ & $29.1 \pm 9.4 \mathrm{a}$ & $2.0 \pm 3.5 \mathrm{a}$ \\
\hline \multirow{2}{*}{ Van, 1997} & B. cinerea & $3.9 \pm 4.7 \mathrm{a}$ & $25.4 \pm 18.1 \mathrm{a}$ & 0 \\
\hline & Water & $0 \mathrm{~b}$ & $18.5 \pm 10.1 \mathrm{a}$ & 0 \\
\hline \multirow[t]{3}{*}{ Lapins, 1997} & B. cinerea & $1.8 \pm 4.3 \mathrm{a}$ & $15.1 \pm 10.1 \mathrm{a}$ & $5.3 \pm 5.0 \mathrm{a}$ \\
\hline & Monilinia laxa & $0 \mathrm{a}$ & $11.8 \pm 14.4 \mathrm{a}$ & $8.0 \pm 6.3 \mathrm{a}$ \\
\hline & Water & $0 \mathrm{a}$ & $8.9 \pm 10.1 \mathrm{a}$ & $8.5 \pm 7.6 \mathrm{a}$ \\
\hline \multirow[t]{3}{*}{ Early Burlat, 1998} & B. cinerea & $1.8 \pm 3.4 \mathrm{a}$ & $51.8 \pm 11.7 \mathrm{~b}$ & $24.3 \pm 10.7 \mathrm{a}$ \\
\hline & M. laxa & $0 \mathrm{a}$ & $76.6 \pm 18.0 \mathrm{a}$ & $1.8 \pm 3.1 \mathrm{~b}$ \\
\hline & Water & $1.1 \pm 2.9 \mathrm{a}$ & $50.9 \pm 17.5 \mathrm{~b}$ & $2.1 \pm 4.9 \mathrm{~b}$ \\
\hline \multirow[t]{3}{*}{ Vista, 1998} & B. cinerea & $0.3 \pm 1.3 \mathrm{a}$ & $16.9 \pm 11.5 b$ & $5.5 \pm 4.3 \mathrm{a}$ \\
\hline & M. laxa & $1.0 \pm 4.4 \mathrm{a}$ & $38.9 \pm 17.0 \mathrm{a}$ & $3.1 \pm 5.3 \mathrm{a}$ \\
\hline & Water & $0.3 \pm 1.3 \mathrm{a}$ & $12.5 \pm 11.7 \mathrm{~b}$ & $5.2 \pm 5.4 \mathrm{a}$ \\
\hline \multirow[t]{3}{*}{ Lapins, 1998} & B. cinerea & $1.7 \pm 2.5 \mathrm{a}$ & $7.1 \pm 6.1 \mathrm{~b}$ & $14.8 \pm 9.9 \mathrm{a}$ \\
\hline & M. laxa & $1.4 \pm 3.0 \mathrm{a}$ & $14.8 \pm 11.0 \mathrm{a}$ & $16.9 \pm 17.2 \mathrm{a}$ \\
\hline & Water & $2.2 \pm 3.2 \mathrm{a}$ & $4.7 \pm 4.8 b$ & $28.3 \pm 19.5 \mathrm{a}$ \\
\hline
\end{tabular}

${ }^{y}$ Mean of three replicates each of 100 fruit \pm standard deviation. Mean values denoted with different letters are significantly different $(P=0.05)$ according to Student Newman Keuls test; comparison between treatments (inoculum) within each cultivar/year.

${ }^{\mathrm{z}}$ Diseases on Vista in 1996 were not distinguished properly and the results are not presented.

rea, M. laxa, and water control pooled), the mean difference in fruit rot between categories 1 and 5 was $29.8 \pm 4.7(P=0.0001)$.

\section{DISCUSSION}

The present experiments showed that cuticular fractures are positively correlated with postharvest fruit rot in sweet cherry, as previously suggested by Glenn and Poovaiah (11) and Sekse (19). Increased rates of fungal rot due to cuticular fractures or similar minute injuries are reported in other fruit crops, (e.g., grape [16] and prune [13]), but only in fruit-to-fruit contact surfaces. Small cuticular fractures also are reported to occur in litchi (22), tomato $(2,23)$, nectarine (10), and apple (9), with proposed increases in risk of infection. Furthermore, the present experiments demonstrated a linear relationship between fungal attack and amount of cuticular fracturing and, to our knowledge, this is the first report quantifying an increase in fungal infection with increasing amount of cuticular fracturing.

Fruit infected with M. laxa dominated after incubation, even in noninoculated fruit and fruit inoculated with $B$. cinerea. Thus, preharvest colonization must have occurred. Preharvest colonization of various fungi in sweet cherry fruit is reported to occur from petal fall to harvest (6), and nonvisible quiescent infections of Monilinia fructicola and $B$. cinerea occur on maturing sweet cherry fruit (1). The most important explanation for the dominance of Monilinia laxa in the present work could be a much higher amount of inoculum of this fungus occurring throughout the season than of $B$. cinerea in the orchard. $M$. laxa is the principal cause of blossom blight in Norwegian cherry orchards, and there is usually a gradual build-up of inoculum due to blossom and fruit infections throughout the season. For $B$. cinerea, most infections seem to occur closer to harvest. In many orchards, the amount of overwintering inoculum of $M$. laxa, especially from mummified fruit, is high throughout the growing season (17). Thus, the total inoculum of $M$. laxa present at harvest is often much higher than that of $B$. cinerea, with a higher risk of fruit being infected by $M$. laxa than by $B$. cinerea .

Unlike fractures in apple and tomato fruit, cuticular fractures in sweet cherry fruit occur later in the ripening season and do not heal and cause russeting. Cuticular fractures develop close to harvest in the period with rapid cell expansion (19); therefore, it is assumed that colonization of fruit by fungal parasites prior to this would not be affected by cuticular fracturing. When comparing fruit within the same category of fracturing, the observed decay after incubation varied distinctly among the different trials. As an example, fruit treated with water only (control fruit) and classified as having no fractures had a disease incidence of 8 to $37 \%$, and fruit with severe fracturing (category 5) had a disease incidence of 15 to $72 \%$. Cultivar and weather prior to harvest may partly explain some of the differences. When fruit are colonized by fungal organisms prior to harvest, wounds probably increase the development of postharvest rots. It is known that the necrotic tissue in the stylar scar is frequently colonized preharvest (6), and resident fungi in moribund and asymptomatic tissue such as the stylar scar can serve as inoculum of fruit with both wounded and intact cuticles (6). Furthermore, preharvest colonization increases cumulatively in fruit during the ripening season (6), and more preharvest colonization in late-ripening sweet cherry cultivars is expected than in cultivars harvested earlier in the season. Lapins is one of the latest-ripening cultivars in Norwegian sweet cherry production. Higher preharvest colonization than for other, earlier-ripening cultivars could explain why Lapins failed to show increased fruit rot with increasing amount of cuticular fractures in 1998. The weather conditions were favorable for establishing latent infections throughout the whole season in 1998, due to frequent precipitation (Table 2).

In the 1998 experiments, there was a high incidence of Mucor rot, especially in the trial with Lapins. The amount of Mucor 
Table 4. Effect of cuticular fracturing on disease incidence (\%) in sweet cherry fruit after treatments with Botrytis cinerea, Monilinia laxa, or water control followed by incubation for 4 to 7 days at $20^{\circ} \mathrm{C}^{\mathrm{w}}$

\begin{tabular}{|c|c|c|c|c|c|c|c|}
\hline \multirow[b]{2}{*}{ Year, cultivar } & \multirow[b]{2}{*}{ Treatment $^{\mathbf{y}}$} & \multicolumn{5}{|c|}{ Incidence by cuticular fracturing category $(\%)^{\mathrm{x}}$} & \multirow[b]{2}{*}{ Linearity $(P)^{\mathrm{z}}$} \\
\hline & & 1 & 2 & 3 & 4 & 5 & \\
\hline \multicolumn{8}{|l|}{1996} \\
\hline \multirow[t]{2}{*}{ Vista } & B. cinerea & 6.7 & 10.0 & 13.3 & 31.7 & 62.1 & 0.0001 \\
\hline & Water & 17.0 & 6.9 & 17.9 & 29.3 & 14.8 & 0.67 \\
\hline \multirow[t]{2}{*}{ Van } & B. cinerea & 26.7 & 38.3 & 48.3 & 54.7 & 90.9 & 0.0001 \\
\hline & Water & 31.0 & 30.0 & 38.3 & 42.3 & 28.6 & 0.78 \\
\hline \multicolumn{8}{|l|}{1997} \\
\hline \multirow[t]{2}{*}{ Van } & B. cinerea & 21.0 & 22.4 & 28.8 & 29.5 & 55.0 & 0.048 \\
\hline & Water & 11.7 & 21.7 & 18.6 & 18.2 & 30.6 & 0.099 \\
\hline \multirow[t]{3}{*}{ Lapins } & B. cinerea & 20.0 & 21.7 & 27.8 & 42.9 & 43.8 & 0.1 \\
\hline & M. laxa & 8.3 & 15.0 & 20.7 & 32.6 & 43.8 & 0.014 \\
\hline & Water & 8.3 & 15.0 & 25.0 & 31.1 & 40.0 & 0.089 \\
\hline \multicolumn{8}{|l|}{1998} \\
\hline \multirow[t]{3}{*}{ Early Burlat } & B. cinerea & 45.8 & 71.2 & 74.6 & 81.7 & 98.2 & 0.0001 \\
\hline & M. laxa & 58.7 & 61.4 & 78.3 & 90.0 & 98.3 & 0.0001 \\
\hline & Water & 31.9 & 36.1 & 63.2 & 67.8 & 71.9 & 0.0042 \\
\hline \multirow[t]{3}{*}{ Vista } & B. cinerea & 8.9 & 18.6 & 21.7 & 27.3 & 36.7 & 0.03 \\
\hline & M. laxa & 36.4 & 37.3 & 43.9 & 45.0 & 52.6 & 0.36 \\
\hline & Water & 20.7 & 10.3 & 10.3 & 14.6 & 34.5 & 0.24 \\
\hline \multirow[t]{3}{*}{ Lapins } & B. cinerea & 16.7 & 16.7 & 30.0 & 26.7 & 29.8 & 0.17 \\
\hline & M. laxa & 16.7 & 28.3 & 46.6 & 32.7 & 43.9 & 0.11 \\
\hline & Water & 36.7 & 25.9 & 36.5 & 45.0 & 30.6 & 0.87 \\
\hline
\end{tabular}

${ }^{w}$ Mean of three replicates.

${ }^{\mathrm{x}}$ Cuticular fracturing on a scale of 1 to 5 , where $1=$ no visible cuticular fracturing and $5=$ severe cuticular fracturing.

${ }^{\mathrm{y}}$ Fruit rot on fruit treated with water was due to preharvest fungal colonization, remaining invisible at time of harvest.

${ }^{\mathrm{z}} P$ values for the orthogonal polynomial for linearity between amount of cuticular fracturing and fruit rot.

rot did not seem to be affected by cuticular fracturing. This was also observed in a trial where sweet cherry fruit were inoculated with Mucor piriformis (unpublished data). The above observation contradicts the belief that Mucor spp. need wounds or aging tissue for infection $(12,15)$. The wet weather during the entire growing season in 1998 most likely stimulated infections of $M$. piriformis in the sweet cherry fruit. In commercial orchards in the region where the experiments were performed, Mucor rot was abundant in 1998. A further explanation for the attack of $M$. piriformis may be the infected fruit used as inoculum sources for Monilinia laxa in general and for $B$. cinerea in one trial in 1998. The fruit may have contained traces of other pathogens, including Mucor piriformis. The latter fungus develops rapidly and, if present, it could have colonized the fruit in advance of Monilinia laxa or B. cinerea.

Disinfection of fruit prior to inoculation may have reduced the attack of fungi other than the ones inoculated. Water in commercial packing machines is commonly chlorinated to reduce postharvest rotting (14). However, it has been stated that surface sterilization of cherry fruit with $\mathrm{NaOCl}$ failed to reduce the amount of resident fungi $(6,7)$. When we dipped fruit in $\mathrm{NaOCl}$ and stored them for 6 days at $2^{\circ} \mathrm{C}$ and 3 days at $20^{\circ} \mathrm{C}$, the incidence of fruit infected by Mucor piriformis was reduced from 16 to $1 \%$ (unpublished data), probably because the fungus at that time had not penetrated the interior tissue of the fruit.

The increase in number of diseased fruit with increasing cuticular fracturing in these experiments was distinct, showing that sweet cherry growers should consider management practices to avoid cuticular fracturing. Preharvest cuticular fractures have been reported to occur after irregular fruit cell expansion close to harvest, as a consequence of irregular water supply to the cherry trees. A regular water supply reduces the amount of cuticular fracturing (18) and subsequently the possibility for postharvest decay; therefore, proper irrigation may indirectly make it possible to reduce the number of fungicide applications prior to harvest.

Cuticular fracturing may play an important role when sweet cherry fruit are immersed in water in the packing line, because cuticular fractures evidently promote postharvest fruit cracking (20). Also, the packing machine water may serve as a reservoir of parasitic fungal organisms, as reported from apple packing machines in Oregon (21). This could increase the number of infections after packing in fruit with high numbers of cuticular fractures in comparison with fruit with less fracturing.

\section{ACKNOWLEDGMENTS}

We thank the technical staff at Ullensvang Research Centre for invaluable help with the experiments.

\section{LITERATURE CITED}

1. Adaskaveg, J. E., Förster, H., and Thompson, D. F. 2000. Identification and etiology of visible quiescent infections of Monilinia fructicola and Botrytis cinerea in sweet cherry fruit. Plant Dis. 84:328-333.

2. Bakker, J. C. 1988. Russeting (cuticle cracking) in glasshouse tomatoes in relation to fruit growth. J. Hortic. Sci. 63:459-463.

3. Børve, J., Sekse, L., and Stensvand, A. 1998. Cuticular fractures as infection sites of $\mathrm{Bo}$ trytis cinerea in sweet cherry fruits. Acta Hortic. 468:737-740.
4. Brown, S., and Wilcox, W. F. 1989. Evaluation of cherry genotypes for resistance to fruit infection by Monilinia fructicola (Wint.) Honey. HortScience 24:1013-1015.

5. Byrde, R. J. W., and Willets, H. J. 1977. The Brown Rot Fungi of Fruit: Their Biology and Control. Pergamon Press, Oxford.

6. Dugan, F. M., and Roberts, R. G. 1994. Etiology of preharvest colonization of Bing cherry fruit by fungi. Phytopathology 84:1031-1036.

7. Dugan, F. M., and Roberts, R. G. 1997. Preharvest fungal colonization affects storage life of Bing cherry fruit. J. Phytopathol. 145:225230.

8. Elad, Y., and Evensen, K. 1995. Physiological aspects of resistance to Botrytis cinerea. Phytopathology 85:637-643.

9. Faust, M., and Shear, C. B. 1972. Fine structure of the fruit surface of three apple cultivars. J. Am. Soc. Hortic. Sci. 97:351-355.

10. Fogle, H. W., and Faust, M. 1975. Ultrastructure of nectarine fruit surfaces. J. Am. Soc. Hortic. Sci. 100:74-77.

11. Glenn, G. M., and Poovaiah, B. W. 1989. Cuticular properties and postharvest calcium applications influence cracking of sweet cherries. J. Am. Soc. Hortic. Sci. 114:781-788.

12. Maas, J. L. 1998. Compendium of Strawberry Diseases. American Phytopathological Society, St. Paul, MN.

13. Michailides, T. J., and Morgan, D. P. 1997. Influence of fruit-to-fruit contact on the susceptibility of French Prune to infection by Monilinia fructicola. Plant Dis. 81:14161424

14. Ogawa, J. M., and English, H. 1991. Diseases of temperate zone tree fruit and nut crops. Univ. Calif. Div. Agric. Nat. Res. Oakland. Publ. 3345 .

15. Ogawa, J. M., Zehr, E. I., Bird, G. W., Ritchie, D. F., Uriu, K., and Uyemoto, J. K. 1995. Compendium of Stone Fruit Diseases. American Phytopathological Society, St. Paul, MN.

16. Percival, D. C., Sullivan, J. A., and Fisher, K. H. 1993. Effect of cluster exposure, berry contact and cultivar on cuticular membrane formation and occurrence of bunch rot (Botrytis cinerea Pers.:Fr.) with 3 Vitis vinifera L. cultivars. Vitis 32:87-97. 
17. Rüegg, J., and Hilber-Bodmer, M. 1997. Monilia und Bitterfäule auf Kirschen 1996: Weiterführende erkentnisse und empfelungen. Schweiz. Z. Obst Weinbau 133:170-173.

18. Sekse, L. 1995. Cuticular fracturing in fruits of sweet cherry (Prunus avium L.) resulting from changing soil water contents. J. Hortic. Sci. 70:631-635.

19. Sekse, L. 1996. Cuticular fracturing in the cherry fruit-causes and consequences. J. Exp. Bot. 47 (Abstr. Suppl May 1996):52.

20. Sekse, L. 1998. Cuticular fractures in fruits of sweet cherry (Prunus avium L.) affect fruit quality negatively and their development is influenced by cultivar and rootstock. Acta Hortic. 468:671-676.

21. Spotts, R. A., and Cervantes, L. A. 1986. Populations, pathogenicity, and benomyl re- sistance of Botrytis spp., Penicillium spp., and Mucor piriformis in packinghouses. Plant Dis. 70:106-108.

22. Underhill, S. J. R., and Simons, D. H. 1993. Lychee (Litchi chinensis Sonn.) pericarp desiccation and the importance of postharvest microcracking. Sci. Hortic. 54:287-294.

23. Young, P. A. 1947. Cuticle cracks in tomato fruits. Phytopathology 37:143-145. 